\title{
REGULATION FEATURES OF STRUCTURE OF LINEAR BLOCK- COPOLYURETHANE COMPOSITES OF HIGH WEAR RESISTANCE
}

\author{
Volodymyr Anisimov ${ }^{1} \bowtie$, Volodymyr V. Anisimov ${ }^{1}$
}

https://doi.org/10.23939/chcht15.01.033

\begin{abstract}
The influence of the main structural parameters (molecular weight and hard blocks content) as well as methods of filling linear block-polyurethanes and their compositions on their strength, deformation, rheological and tribotechnical characteristics has been studied. A complex approach to produce polyurethane compositions of improved wear resistance has been suggested.
\end{abstract}

Key words: linear block-polyurethane, molecular weight, hard block, filler, wear resistance.

\section{Introduction}

Linear block-polyurethanes, which entered the world market over fifty years ago, are increasingly used in industry. The annual growth rate of their production is $3-5 \%$, and the composition range is rapidly expanding $[1,2]$.

Specific chemical structure of polyurethanes associated with their block copolymer structure (there is a superposition of elastomer and plastic technologies), on the one hand, offers great potential for variations in the composition of their macromolecules and, consequently, their properties. On the other hand, it greatly complicates the systematization of data on their interrelations [3]. Moreover, the compositions of polyurethane-based materials have mostly been developed empirically and data on the relationships between their compositions and properties are often incomplete and contradictory $[4,5]$. Thus, assessment of the polyurethanes tribotechnical characteristics depending on the hardness index is commonly accepted today $[6,7]$. However, polyurethanes of the same structure but of different ability of the oligoglycolic component for crystallization can have almost twice different values of hardness, and, accordingly, values of elasticity and coefficient of friction, or have the same hardness but completely

\footnotetext{
${ }^{1}$ Ukrainian State University of Chemical Technology

8, Gagarina Ave., 49005 Dnipro, Ukraine

vn7anisimov@ukr.net

(c) Anisimov V., Anisimov VV., 2021
}

different morphology. To improve tribotechnical characteristics of polyurethanes the solid dispersed (nano-dispersed) compounds, liquids (lubricants), highmodulus fibers, and others are inserted. $[1,2,6,8]$. There are numerous publications on the subject, however, their results are scattered and lack generalization, especially when it comes to the production of polyurethane composites for tribotechnical purposes. Therefore, the choice of a rational matrix of linear block-polyurethane composites of increased wear resistance, taking into account the macromolecular structure, nature of initial components and methods of modification is an urgent scientific and technological problem, which is of great practical importance for almost every industry.

This study is aimed at the development of linear block-polyurethanes and polyurethane-based composites of improved wear resistance through variations in their macromolecular structures, nature and type of starting constituents, and filling techniques.

\section{Experimental}

Block-polyurethanes (BPU) synthesized by JSC "Polimersintez" and firm "Vitur" were chosen as objects of researches. BPU of different molecular structures were synthesized. Synthesis was carried out from oligomeric esters (synthesized from adipic acid and glycols of methylene series of different nature oligo(ethylene adipate) of molecular weight $\sim 2000$ $\left(\mathrm{OEGA}_{2000}\right)$, oligo(1,4-butylene adipate) of molecular weight $\sim 500$ and $\sim 2000 \quad\left(\mathrm{OBGA}_{500}, \mathrm{OBGA}_{2000}\right)$, oligo(1,4-butylene ethylene adipate) of molecular weight $\sim 2000 \quad\left(\mathrm{OEBGA}_{2000}\right)$ and oligomeric ether oligo(tetramethylene ether) glycol of molecular weight $\sim 1000\left(\mathrm{OOTMG}_{1000}\right)$, synthesized from tetrahydrofuran). Urethane groups were created from 4,4'- methylene diphenyl diisocyanate (MDI), for obtaining block structure of BPU low molecular weight glycol - 1,4 butanediol (butylene glycol) (BD) was inserted. Blockcopolymer molecule consists of parts that differ in flexibility and repeat. Elastic blocks are formed from 
flexible parts (oligoethers or oligoesters). Rigid blocks are formed as a result of the self-organization of urethane groups.

Physical and mechanical properties of the polyurethanes were estimated on Instron TT-DM-4 universal machine. The hardness of the test materials was measured by the TM-2 device of indenter type.

The BPU tribotechnical characteristics were studied on a disk friction machine using "disk-finger sample" technique [9] at the slip speed $v=0.4 \mathrm{~m} / \mathrm{s}$ and specific load $P=0.2 \mathrm{MPa}$.

The results of the study were computer-processed using the software package MathCAD.

\section{Results and Discussion}

As it was earlier found $[10,11]$, the molecular weight and ratio of hard segments are the main characteristics for determining the BPU properties.

Block-polyurethanes materials of a molecular weight that corresponds to intrinsic viscosity $[\eta]=0.8-$ $1.1 \mathrm{dl} / \mathrm{g}$ have the most optimal structural ordering, they exhibit a minimum value of wear at dry friction, friction in the water and friction under the abrasive particles

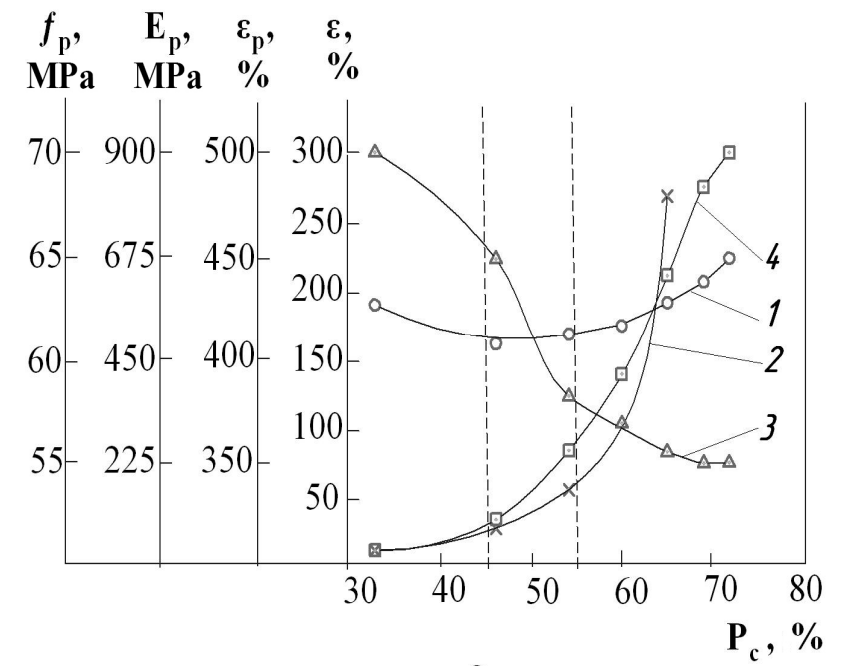

a) action. They also show the lowest coefficient of friction and increased heat resistance (Fig. 1).

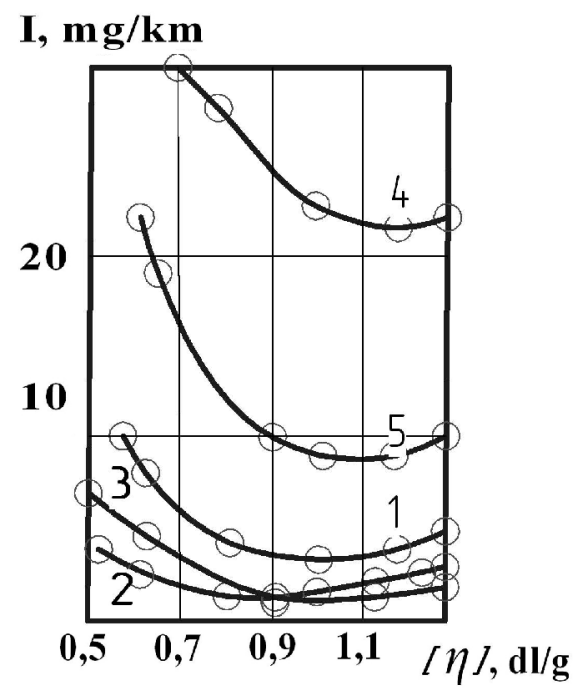

Fig. 1. Dependences of the block-polyurethanes wear rate on intrinsic viscosity $[\eta]$ : $\mathrm{OBGA}_{500}: \mathrm{BD}: \mathrm{MDI}=1: 0.5: 1.5(1)$;

OBGA $_{500}: \mathrm{BD}: \mathrm{MDI}=1: 1.5: 2.5(2) ; \mathrm{OBGA}_{500}: \mathrm{BD}: \mathrm{MDI}=1: 3: 4$

(3); OEGA $_{2000}: \mathrm{BD}: \mathrm{MDI}=1: 0.5: 1.5$ (4) and

$\mathrm{OEGA}_{2000}: \mathrm{BD}: \mathrm{MDI}=1: 4: 5(5) . v=0.4 \mathrm{~m} / \mathrm{s}, P=0.2 \mathrm{MPa}$

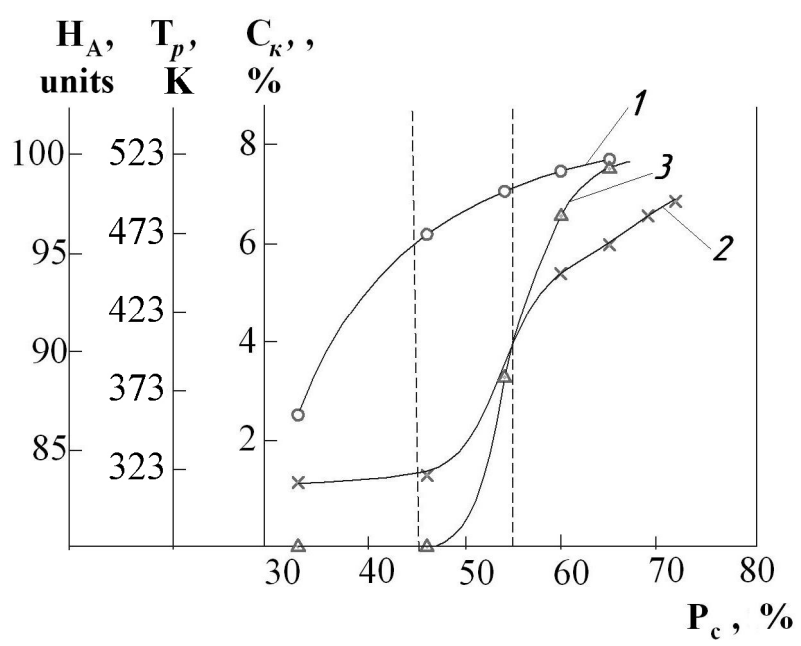

b)

Fig. 2. Dependences of physico-mechanical characteristics of $\mathrm{OBGA}_{500}$-based BPU on the hard blocks content: conditional stretching strength $\left(f_{p}, 1 \mathrm{a}\right)$; elasticity modulus at stretching $\left(E_{p}, 2 \mathrm{a}\right)$; relative elongation at rupture $\left(\varepsilon_{p}\right.$, 3a); residual elongation $(\varepsilon, 4 \mathrm{a})$; Shore hardness $\left(H_{A}, 1 \mathrm{~b}\right)$; Vicat softening temperature $\left(T_{p}, 2 \mathrm{~b}\right)$; degree of crystallinity $\left(\mathrm{C}_{\kappa}, 3 \mathrm{~b}\right)$

Fig. 2 shows dependence between physicomechanical characteristics of BPU based on $\mathrm{OBGA}_{500}$ and the morphological structure parameters. When content of rigid blocks increases, the residual elongation $\varepsilon$ of polyurethane block-copolymers increases rapidly (curve 4a). The same rapid growth is observed for the elasticity modulus at stretching $E_{p}$ (curve $2 \mathrm{a}$ ), the Shore hardness $H_{A}$ (curve $1 \mathrm{~b}$ ), the Vicat softening temperature $T_{p}$ (curve $2 \mathrm{~b}$ ) and the degree of crystallinity $C_{\kappa}$ (curve $3 b)$. The relative elongation at rupture $\varepsilon_{r}$ is reduced with the increase in the content of hard blocks (curve 3a). The dependence of $\varepsilon_{r}$ on $P_{c}$ has an S-like character - we can observe two points of inflection: at $P_{c}=45 \%$ and $P_{c}=55 \%$. The dependence of the conditional stretching 
strength $f_{p}$ on $P_{c}$ has an extreme character with a minimum in the region of $P_{c}=45-55 \%$ (curve 1a).

Block-polyurethanes synthesized from oligodiol OBGA $_{500}$ at $P_{c}=33 \%$ have minimum values of hardness and elasticity modulus of the material (curves $1 \mathrm{a}, 1 \mathrm{~b})$. The Shore hardness is $80-87$ units, the elasticity modulus at stretching is $15-20 \mathrm{MPa}$.

In the conditions of friction without lubrication there is a "catastrophic" wear due to the "foldering", which is characterized by the formation of destruction cells in the form of "bundles" and "rollers" on the polymer surface. The surface of such samples has "crests and pits", which alternate in the direction perpendicular to slipping, as well as deep debris traces in the surface layers (Fig. 3a). The wear intensity and the BPU friction coefficient of this composition are low (Fig. 4).

The area of actual contact, measured by the Mehau method at $0.2 \mathrm{MPa}$ loading, reaches the limit values, which are close to the values of nominal area (90-95\%).

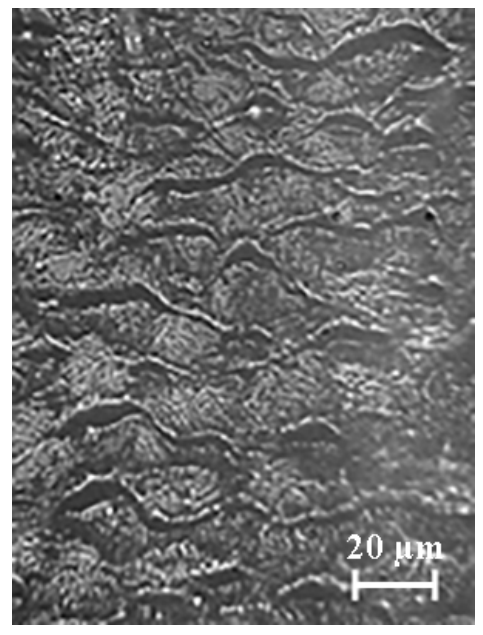

a)

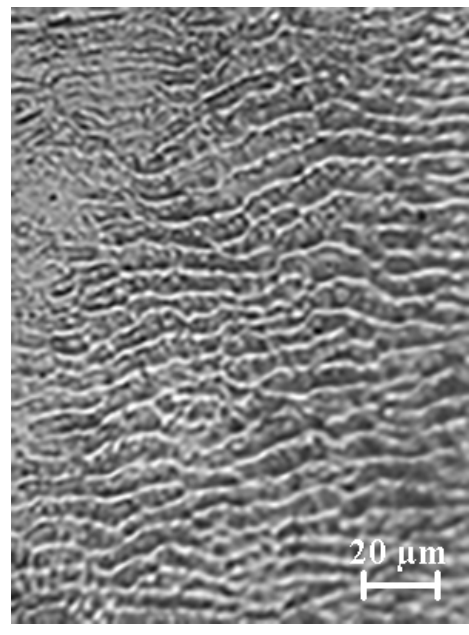

b)

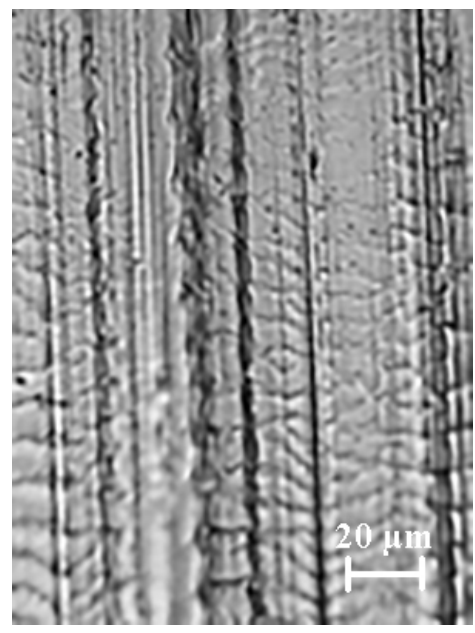

c)

Fig. 3. Micrographs of $\mathrm{OBGA}_{500}$-based $\mathrm{BPU}$ with different hard blocks content (friction without lubrication): $P_{c}=33-45 \%(\mathrm{a}) ; P_{c}=45-55 \%(\mathrm{~b})$ and $P_{c}>55 \%$ (c)

Fig. 4. Dependences of $\mathrm{OBGA}_{500}$-based BPU wearing intensity in conditions of friction without lubrication $(P=0.2 \mathrm{MPa}, v=0.4 \mathrm{~m} / \mathrm{s})$ on the hard blocks content at the fixed values of friction coefficient $f: 0.25$ (1); 0.50 (2); 1.00 (3); $1.50(4)$ and $2.00(5)$

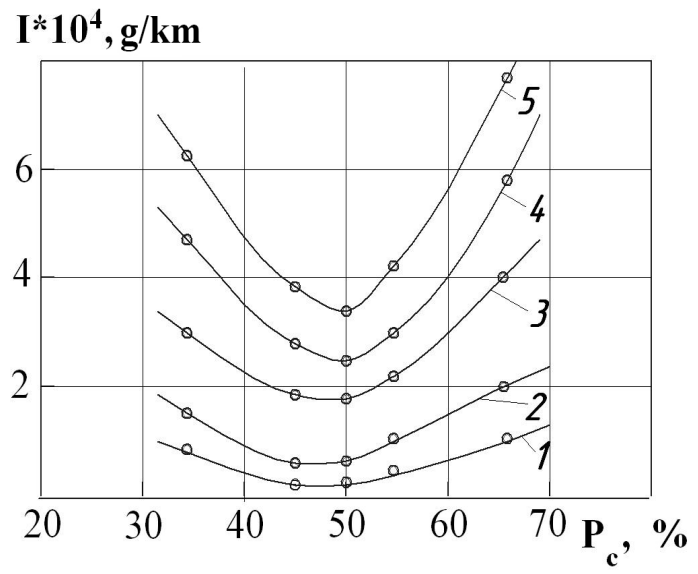

fixed scattering angles of $19.4^{\circ}$ and $23.5^{\circ}$ with parameters of the crystal lattice 0.46 and $0.38 \mathrm{~nm}$ are observed in the BPU structure. A wearing mechanism due to tiredness (Fig. 3b) is a primary one for such materials. During wearing a finely dispersed powder is obtained.

Further increase of 1,4-butanediol content in the reaction mixture during the BPU synthesis and the hard blocks content of $60-70 \%$ leads to the formation of $\mathrm{X}$-ray diffraction the evidence crystalline formations at (Fig. 2, curves 1b, 2a, 2b). By method of wide-angle

butanediol content of $0.5-1.0 \mathrm{~mol}$, the part of hard blocks is $45-55 \%$. Block-polyurethanes with the rigid locks contents $P_{c}=45-55 \%$ have minimum values of ar rate (Fig. 4). The hardness reaches $\sim 100$ according to Shore A, the elastic modulus at stretching is $\sim 200 \mathrm{MPa}$, the softening temperature increases to $413 \mathrm{~K}$ 
polymers in which the elasticity modulus at stretching exceeds $800 \mathrm{MPa}$ and hardness increases to $\sim 50$ units by Shore (scale D) (Fig. 2, curve 1b).

Traces of microcircuits in the form of long cavities located along the direction of friction (Fig. 3c) were found on the friction surfaces by optical microscopy. We can observe a decrease in the wear resistance level at $P_{c}>60 \%$ (Fig. 4). In this concentration range there is a change in such properties as relative and residual elongation. Crystallinity $C_{k}$ of materials for $P_{c}>60 \%$ reaches its maximum values of $\approx 8 \%$ (Fig. 2, curves $3 \mathrm{a}, 4 \mathrm{a}, 3 \mathrm{~b}$ ).

Similar patterns of the $\mathrm{P}_{c}$ influence on the properties are observed in the conditions of BPU wearing in the flow of abrasive particles at the angle of attack $\alpha=15-90^{\circ}$ and flow velocity $v=38-76 \mathrm{~m} / \mathrm{s}$ (Fig. 5).

At minimum values of $P_{c}$ in the range of 33$45 \%$, there is a rather sharp increase in the intensity of gas-abrasive wearing with an increase in the content of hard blocks.

For $P_{c}$ values in the range of $45-55 \%$ with the increase in hard blocks content we can observe a slight change in the intensity of gas abrasive wearing with signs of stabilization - there is a plateau in the range of $P_{c}=45-55 \%$.

Further increase in the content of BPU hard blocks $\left(P_{c}>55 \%\right)$ is characterized by a new sharp increase in the intensity of gas-abrasive wearing. This pattern is observed in the case of all investigated angles of attack and flow velocities of abrasive particles. BPU have the highest intensity of wear at $\mathrm{P}_{\mathrm{c}}>55 \%$. For some materials there is a transition to the region of negative values of the wearing intensity (Fig. 5, curves 3, 4, 5).
Such anomalies are the result of the abrasive particles immersion into the polymer material (dashed fragments, Fig. 5).

Few photos of the BPU surfaces of the studied samples after experiments at flow velocity of abrasive particles of $76 \mathrm{~m} / \mathrm{s}$ are shown in Fig. 6a (the most intensive wear of polyurethane samples is observed in these conditions). The photos represent the state of worn surfaces of BPU for polymers of different morphology: with a minimum content of $P_{c}(33-40 \%)$, with $P_{c}=45-$ $55 \%$ (the area of wear intensity stabilization) and with maximum content of $P_{c}(>55 \%)$.

At $P_{c}=33-45 \%$ for small angles of attack $\left(\alpha=15^{\circ}\right)$ (Fig. 6a) the surfaces with small, rounded, wave-like vertices, formed by the joint effect of multiple elastic deformation of the sample surface layer of polymer under the action of scratching abrasive particles, are characteristic. On the surface of the samples, there is likely to be a joint action of fatigue mechanism and the mechanism of abrasive wearing. At $\alpha=45-90^{\circ}$ (Figs. $6 \mathrm{~b}, \mathrm{c})$, there is a sharp line of a rather large wave-like surface with smoothed vertices. The dimensions of the wave-shaped vertices increase accordingly at transition to $\alpha=90^{\circ}$. At the angle of attack $\alpha=90^{\circ}$ we observe a clear, rather deep furrow with deformed polymer on both sides. Immersed abrasive particles are visible on vertices (Fig. 6c). The destruction of the surface layer in the contact area mostly occurs as a result of multiple deformations of stretching compression and shear rather than the action of cutting abrasive particles, which in turn leads to a low-level tiring destruction of the BPU. This is evidenced by low values of wearing intensity of these materials (Fig. 5).

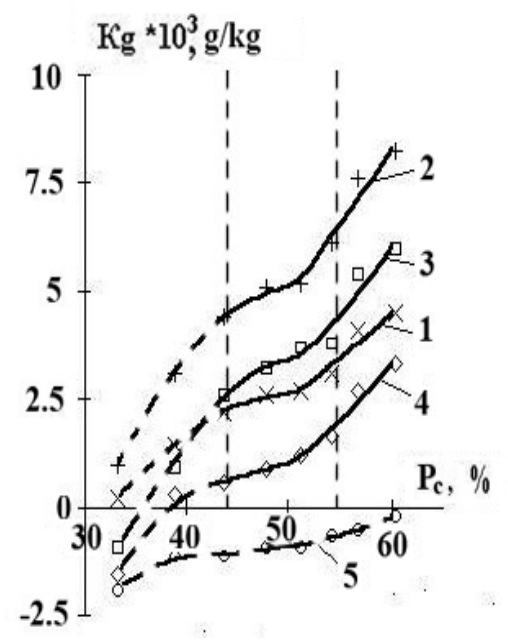

a)

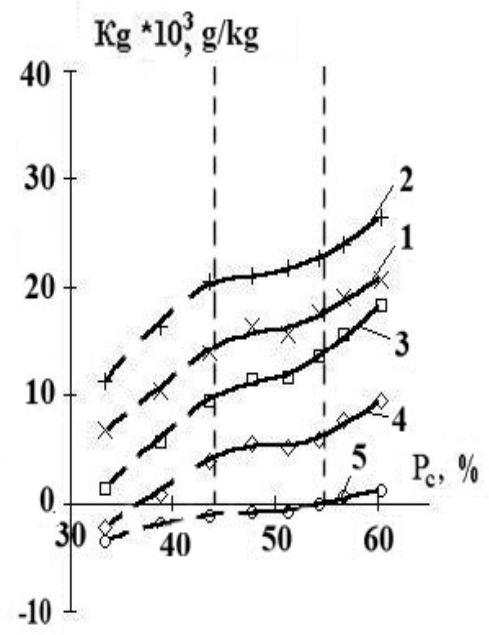

b)

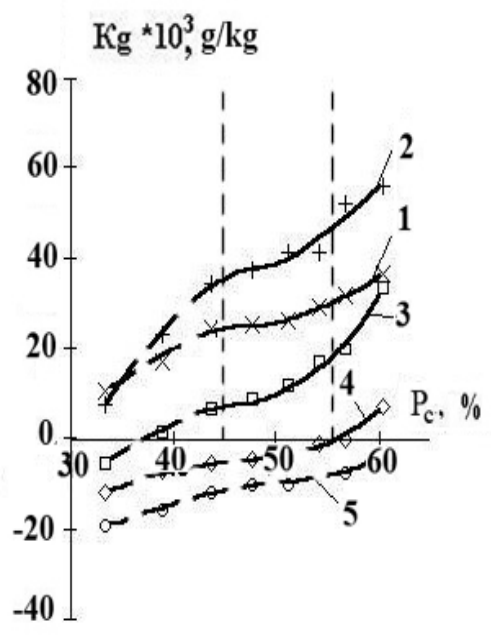

c)

Fig. 5. Dependences of gas-abrasive wearing intensity of $\mathrm{OBGA}_{500}$-based BPU on the content of hard blocks at abrasive particles flow velocity of $38 \mathrm{~m} / \mathrm{s}(\mathrm{a}), 57 \mathrm{~m} / \mathrm{s}$ (b) and $76 \mathrm{~m} / \mathrm{s}$ at different angles of attack: $15^{\circ}(1) ; 30^{\circ}(2)$; $45^{\circ}(3) ; 60^{\circ}(4)$ and $90^{\circ}(5)$ 
An analysis of the material surfaces with $P_{c}=45$ $55 \%$ (Figs. 6b, e, h) shows that for small angles of attack $\left(\alpha=15^{\circ}\right)$ they have a pattern that resembles the effect of the mixed wearing mechanism. However, wave-like vertices have a sharper appearance, and it can be assumed that the part of the abrasive component in the wearing mechanism of this BPU is higher than that of polymers with a minimum content of $P_{c}$. The increase in the material hardness increases the stress concentration in points of the abrasive particles contact with the BPU surface. In this case, suitable conditions for the occurrence of the abrasive wearing mechanism are formed. The intensity of gas-abrasive wearing increases. Like in the previous group of polymers, the stripe of rounded waves appears on the surface of the samples at the angles of attack $\alpha=45^{\circ}$ and $\alpha=90^{\circ}$ (Figs. $6 \mathrm{e}, \mathrm{f})$, the smooth peaks of which indicate the preference of the tiring wearing mechanism. Dimensions of waves are by order of magnitude smaller than those of the BPU, discussed above; in the latter case it can be explained by higher values of the elasticity modulus at stretching $E_{r}$ and lower values of relative elongation at rupture $\varepsilon_{r}$ (Fig. 2).

For the samples with $P_{c}>55 \%$ (Figs. $6 \mathrm{~g}, \mathrm{~h}, \mathrm{i}$ ) at all angles of attack an intensive micro cutting and sctatching abrasive wear by the sharp edges of the river sand is observed. The worn surface is like flat plane with a large number of small smoothed waves.

Thus, according to the above-mentioned physicomechanical and tribotechnical characteristics during wearing of the $\mathrm{OBGA}_{500}$-based BPU in the conditions of friction without lubrication, friction in water and friction under the abrasive particles action, two characteristic values of $P_{c}$ can be distinguished, which correspond to a substantial change in the character of the majority of the above dependences (Figs. 2, 4, and 5). These values are $P_{c 1}=45 \%$ and $P_{c 2}=55 \%$, respectively, and the whole interval $P_{c}$ from 33 to $70 \%$, within which the research was performed, can be conditionally divided into three regions: 1) $P_{c}<P_{c 1}$; 2) $P_{c 1} \leq P_{c} \leq P_{c 2}$; 3) $P_{c}>P_{c 2}$.

$$
P_{c}=33-45 \%
$$

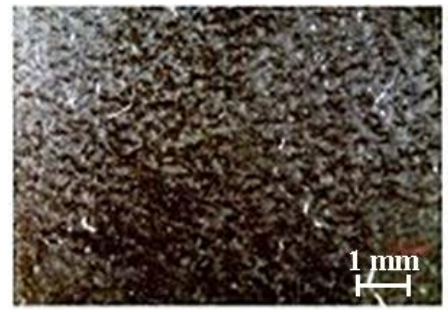

a)

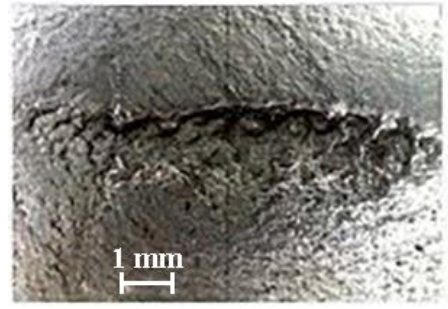

b)

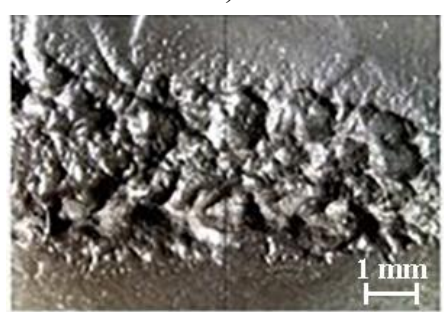

c)
$P_{c}=45-55 \%$

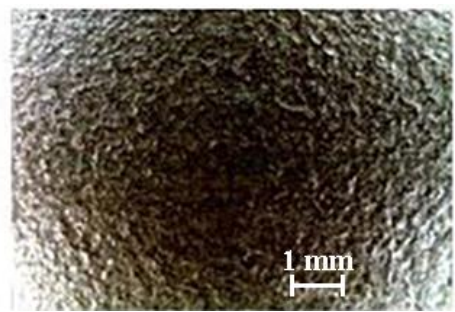

d)

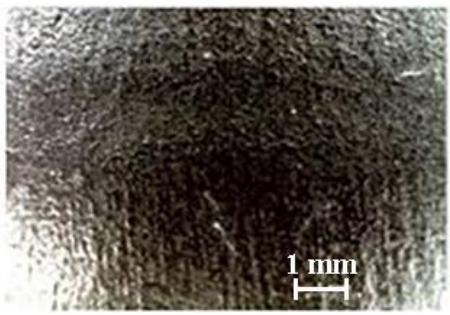

e)

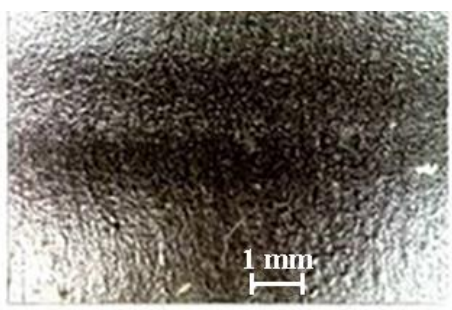

i)
$P_{c}>55 \%$

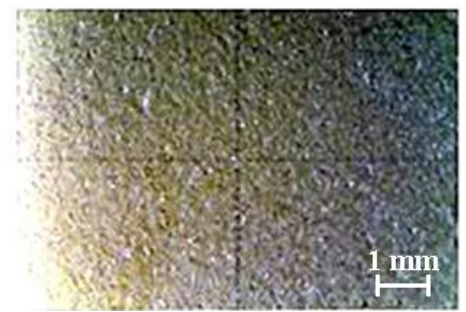

g)

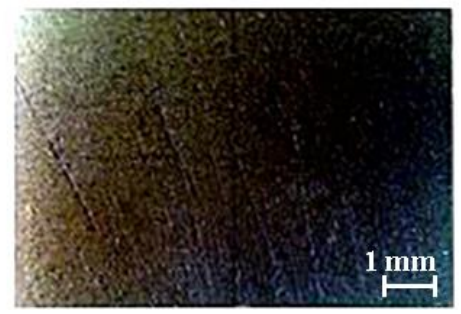

h)

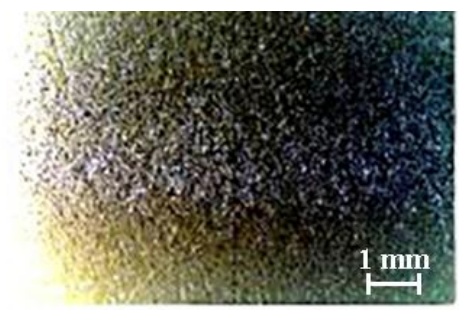

f)

Fig. 6. Characteristic surfaces of $\mathrm{OBGA}_{500}$-based BPU with different contents of hard blocks at abrasive particles flow velocity of $76 \mathrm{~m} / \mathrm{s}$ and different angles of attack: $15^{\circ}(\mathrm{a}, \mathrm{d}, \mathrm{g}) ; 45^{\circ}(\mathrm{b}, \mathrm{e}, \mathrm{h})$ and $90^{\circ}(\mathrm{c}, \mathrm{f}, \mathrm{i})$ 
Similar studies were performed for polyurethane systems based on $\mathrm{OBGA}_{2000}, \mathrm{OEGA}_{2000}, \mathrm{OEBGA}_{2000}$, and $\mathrm{OOTMG}_{1000}$. It is established that character of the dependences of deformation-strength, thermomechanical and tribotechnical properties of the studied BPU on the content of hard blocks is characterized by the presence of two concentration points $P_{c 1}$ and $P_{c 2}$. The concentration $P_{c 1}$ corresponds to the moment of the appearance of bound structure formed by the microphase of hard blocks (MFRB) (MFRB percolation threshold). The concentration of $P_{c 2}$ corresponds to the moment of the appearance of rigid and bound structure formed by the MFRB (MFRB percolation threshold).

Behavior of BPU in the rigid phase interval $P_{c}<P_{c 1}, P_{c 1} \leq P_{c} \leq P_{c 2}$ and $P_{c}>P_{c 2}$ differs essentially. At minimal contents, when $P_{c}<P_{c 1}$, the BPU properties are determined by elastic phase (hard blocks are located in the polymer separately). At the content $P_{c 1} \leq P_{c} \leq P_{c 2}$ a structural organization is formed in which the elastic and rigid phases are functioning synergistically. BPU with these parameters of geometric phase morphology provide a high level of deformation-strength, tribotechnical, and other properties. At the further growth of $P_{c}\left(P_{c}>P_{c 2}\right)$, the properties of BPU are determined by rigid phase, therefore, we can observe a decrease in the elasticity, increase in hardness and hysteresis losses. Thus, it is obvious for the studied BPU systems, that the polymers with the contents of hard blocks $P_{c 1} \leq P_{c} \leq P_{c 2}$ are optimal from the standpoint of the relationship between deformation-strength, thermomechanical and tribotechnical characteristics.

Percolation threshold values for the investigated BPU of different molecular and topological structures are given in the Table.

Percolation threshold values for BPU

\begin{tabular}{|c|c|c|c|}
\hline \multirow{2}{*}{ Oligoglycol for BPU } & $\begin{array}{c}\text { Degree of crystallinity } C_{\boldsymbol{\kappa}}, \% \\
(\text { at } n=0)\end{array}$ & \multicolumn{2}{|c|}{ Percolation threshold values, $\%$} \\
\cline { 3 - 4 } & $<0.2$ & $P_{c 1}$ & \multicolumn{2}{c|}{$P_{c 2}$} \\
\hline OBGA $_{500}$ & $\approx 20.0$ & 35 & 40 \\
\hline OBGA $_{2000}$ & $\approx 9.0$ & 25 & 42 \\
\hline OEGA $_{2000}$ & $\approx 0.2$ & 24 & 42 \\
\hline OEBGA $_{2000}$ & $<0.2$ & 30 & 50 \\
\hline OOTMG $_{1000}$ & & & \\
\hline
\end{tabular}

Data in the Table indicate that with an increase in the molecular weight of oligoglycol $\left(\mathrm{OBGA}_{500}\right.$ and OBGA $\left._{2000}\right)$ the values of the percolation threshold $P_{c 1}$ and $P_{c 2}$ are shifted towards smaller values, while the increase in the degree of crystallinity of the BPU shifts $P_{c 1}$ towards higher values.

The found dependences of changes in the level of physico-mechanical properties of BPU with rational parameters of geometric phase morphology are mainly linear, that allows, using method of interpolation, to precisely determine the properties of the polymers and predict their work depending on the exploitation conditions.

Thus, the study of tribotechnical characteristics and wear pattern of the BPU as a function of the hard blocks concentration revealed that extremes characterized by the minimal values of wear rate, including abrasive wear, and minimal friction coefficient correspond to the optimal concentration of hard blocks (Table).

Hence, through adjusting the structural parameters, such as molecular weight and ratio of hard blocks, it is possible to produce materials with preset performance characteristics at the synthesis stage. This approach has been used as a base in developing brand compositions of linear block-polyurethanes VITUR ${ }^{\mathrm{TM}}$.
Filling BPU with solid lubricants (graphite, molybdenum disulfide, PTFE, etc.) and epoxy-phenolic oligomers provides high wear resistance and good antifriction characteristics under the conditions of dry friction, allowing to increase the upper temperature limit of their efficiency by 313-323 K [12]. Fine powders of alloys based on iron, nickel, and copper were introduced to increase the thermal conductivity.

The introduction of a polyelectrolyte complex (PEC) based on sodium polyacrylate and vinyl ammonium chloride into the composition contributes to the penetration of water and moisture from the environment into the network structure of the lyophilic PEC. This leads to a concentration of the working fluid on the working surface of the material and promotes the formation of a separating liquid film between the friction surfaces. As a result, there is a decrease in the coefficient of conjugation friction, and an increase in durability.

To reduce the viscosity of the melt, still bottoms of the production of $\mathrm{C}_{17}-\mathrm{C}_{21}$ fraction higher aliphatic amines were injected into the BPU. These materials had high fluidity and formability, which enables the production of large-size products of complex shapes.

Final processing of BPU in thermal fields of various intensity (exposure in the heat chamber, expo- 
sure to infrared rays and laser light) improves the resistance of polyurethane compositions to wear by friction in water by $5-10$ times.

\section{Conclusions}

It has been established that at the present time the integral and comfortable in practical terms system of interconnection between structure and properties of polyurethanes is absent; the accepted estimations of tribological characteristics of polyurethanes, depending on hardness or elasticity, do not take into account the peculiarities of their molecular structure and the nature of the initial monomers.

The interrelation between structural organization parameters of block-copolyurethanes from oligoether and oligoesters of different chemical structure (based on ethylene glycol, butylene glycol and their mixture) and level of deformation-strength, thermomechanical and tribological characteristics in the conditions of friction without lubrication, as well as the action of the abrasive environment, was studied. It is proposed to consider the content of hard blocks as the main parameter of BPU geometric phase morphology. With the increase in the oligoglycol molecular weight $\left(\mathrm{OBGA}_{500}\right.$ and $\left.\mathrm{OBGA}_{200}\right)$, the values of the percolation threshold $P_{c 1}$ and $P_{c 2}$ are shifted towards smaller values, and the increase in the degree of crystallinity of the BPU, on the contrary, displaces $P_{c 1}$ towards higher values.

The choice of rational parameters of the structural organization of the block-copolyurethane matrix with increased wear and abrasive resistance, which is stable under various exploitation conditions (friction without lubrication, wear in abrasive particles stream), on the basis of the studied "composition-structure-property" interconnection is grounded.

Conditions for the formation of rational phase morphology $\left(P_{c 1} \leq P_{c} \leq P_{c 2}\right)$ were established, under which, on the one hand, there is the greatest probability of hard blocks microphase properties realization in terms of providing high strength, and on the other hand, preserving the properties of the polymer-matrix in terms of sufficient elasticity takes place.

Industrial composites based on BPU (of rational phase morphology) were developed, filled with fine dispersed graphite, aminowax, fluoroplastics, polyelectro- lyte complex, metal powder, and epoxy-phenolic oligomers. The compositions are characterized by high wear resistance under conditions of friction without lubrication, minimum coefficient of friction values, high coefficient of thermal conductivity, low sensitivity to share stress and extended temperature interval of processing.

\section{References}

[1] Skakun Y., Nizelsky Y.: Polimernyi Zh., 2007, 1, 3.

[2] Shtompel V., Kercha Y.: Struktura Lineynykh Polyuretanov. Naukova dumka, Kyiv 2008.

[3] Kuleznev V., Morozov Yu.: Kauchuk i Rezina, 2007, 6, 29.

[4] Zonnenshteyn M.: Poliuretany. Sostav, Svoistva,Pproizvodstvo, Primenenie, Professiya, Moskva 2018.

[5] Shumskiy V., Ignatova T., Kosyanchuk L. et al.: Polimernyi Zh., 2017, 39, 24

[6] Kercha Yu., Yakovenko A., Gayduk R. et al.: Plasticheskie Massy, 1995, 4, 15.

[7] Kwiatkowski K., Nachman M.: Polymers, 2017, 9, 705. https://doi.org/10.3390/polym9120705

[8] Zhao Z., Guo Q., Pan G.: Polym. Polym. Compos., 2012, 20, 575. https://doi.org/10.1177/096739111202000701

[9] Tishchenko G., Kurachenkov V., Anisimov V. et al.:

Sovershenstvovanie Metodov Issledovaniya Fiziko-Khimicheskikh

Svoistv Polymernykh Materialov i Zashchitnykh Pokrytiy.

NIITEKhIM, Moskva 1985.

[10] Letunovskiy M., Strahov V., Anisimov V. et al.: Plasticheskie Massy, 1987, 9, 23.

[11] Anisimov V., Semenets A., Letunovskiy M., Strahov V.: Phyziko-Khimichna Mekhanika Materialiv, 2002, 1, 79.

[12] Anisimov V.: Materialy. Tehnologii. Instrumenty, 2013, 18, 38.

Received: June 06, 2019 / Revised: July o7, 2019 / Accepted: December 22, 2019

\section{ОСОБЛИВОСТІ РЕГУЛЮВАННЯ СТРУКТУРИ ЛІНІЙНИХ БЛОК-КОПОЛІУРЕТАНОВИХ КОМПОЗИТІВ ПІДВИЩЕНОЇ ЗНОСОСТІЙКОСТІ}

Анотація. Досліджено вплив головних структурних параметрів (молекулярної маси та вмісту жорстких блоків) а також методів наповнення лінійних блок-кополіуретанів та їх композицій на рівень деформаційно-міџнісних, реологічних $i$ триботехнічних характеристик. Запропоновано комплексний підхід до отримання поліуретанових композищій з підвищеною зносостійкістю.

Ключові слова: лінійний блок-кополіуретан, молекулярна маса, жорсткий блок, наповнювач, зносостійкість. 